\title{
Seeking Biomarkers of Early Childhood Malnutrition's Long-term Effects
}

\author{
Pedro A. Valdés-Sosa MD PhD DrSc, Janina R. Galler MD, Cyralene P. Bryce MD, Arielle G. Rabinowitz MM, \\ María L. Bringas-Vega PhD, Nibaldo Hernández-Mesa MD PhD, Alberto Taboada-Crispi PhD
}

\begin{abstract}
Protein-energy malnutrition affects one in nine people worldwide and is most prevalent among children aged less than five years in low-income countries. Early childhood malnutrition can have damaging neurodevelopmental effects, with significant increases in cognitive, neurological and mental health problems over the lifespan, outcomes which can also extend to the next generation. This article describes a research collaboration involving scientists from five centers in Barbados, China, Cuba and the USA. It builds on longer-term joint work between the Barbados Nutrition Study (which, over a 45-year span, has extensively documented nutritional, health, behavioral, social and economic outcomes of individuals who experienced protein-energy malnutrition in the first year of life and healthy controls from the same classrooms and neighborhoods) and the Cuban Neuroscience Center (which has developed low-cost brain imaging methods that can be readily used in low income settings to identify biomarkers for early detection and treatment of adverse consequences of childhood malnutrition).
\end{abstract}

This collaboration, which involved Barbadian, Cuban and US scientists began in the 1970s, when quantitative EEG techniques were

\section{INTRODUCTION}

Protein-energy malnutrition (PEM) is caused by insufficient protein and calorie consumption, resulting in impaired protein synthesis. Its most severe clinical forms are marasmus and kwashiorkor. Marasmus is characterized by markedly low weight for age, dehydration, chronic diarrhea and stomach shrinkage. Kwashiorkor is characterized by fluid retention, extended abdomen, irritability, and failure to grow and gain weight.[1]

Globally, malnutrition continues to impact large numbers of children aged less than five years in low-resource settings. While low weight-for-age levels have been reduced to $22.9 \%$ over the past decade, 155 million children aged $<5$ years have low stature for age, and 52 million have low weight for age, with more than half of these children living in South Asia.[2] PEM not only causes physical and metabolic changes, it also causes long-term cognitive and behavioral problems that can persist over the lifespan and across generations. Thus, it is important to study its effects on the central nervous system using the latest technologies and to develop targeted interventions that can reverse or reduce these adverse consequences.

IMPORTANCE This 45-year study-ongoing-was made possible by collaboration among Barbadian, Cuban and US scientists. It is the first to use quantitative EEG to assess early childhood malnutrition's long-term neurocognitive effects and identify biomarkers of increased risk for related sequelae, supporting improved targeting of preventive efforts. Since EEG is relatively inexpensive and available, this is particularly promising for developing countries. applied to EEG data collected in 1977-78, at which time study participants were aged 5-11 years. These EEG records were never fully analyzed but were stored in New York and made available to this project in 2016. These data have now been processed and analyzed, comparing EEG findings in previously malnourished and control children, and have led to the identification of early biomarkers of longterm effects of early childhood protein-energy malnutrition. The next stage of the project will involve extending earlier work by collecting EEG recordings in the same individuals at ages $45-51$ years, 40 years later, and comparing findings to earlier data and to these individuals' behavioral and cognitive outcomes. Quantitative EEG biomarkers of the effects of protein-energy malnutrition may help identify children at greatest risk for early malnutrition's adverse neurodevelopmental effects and inform development of targeted interventions to mitigate the long-term adverse effects of protein-energy malnutrition in developing countries.

KEYWORDS Protein-energy malnutrition, electroencephalography, EEG, biomarkers, neurosciences, Barbados, Cuba, USA

\section{PROBLEM AND SCOPE}

For more than four decades, the Barbados Nutrition Study (BNS) has followed individuals who suffered from PEM in their first year of life and a control group matched by age, sex and handedness, to examine the consequences of infant PEM for health status, cognition and behavior over the lifespan.[3-5] Malnutrition studies, including BNS, suggest that early childhood malnutrition can have lifelong impacts, even affecting subsequent generations.[6-9] Improved public health measures have helped increase the number of childhood survivors of PEM, but resulting health, cognitive and behavioral problems often persist. For example, diabetes and attention deficit disorders are four times more common in people who suffered from malnutrition as infants.[6]

Early biomarker identification of children at greater risk of impaired health, cognition and behavior following PEM can facilitate effectiveness of interventions to prevent such adverse outcomes. While two modern neuroimaging techniques-MRI and positron emission tomography - can be employed, both are costly and not easily attained in countries with limited economic resources. [10] In contrast, EEG is a portable, noninvasive and relatively inexpensive technique that can potentially be used for this purpose.

Quantitative EEG (qEEG) is based on the spectrum of signals obtained from electrodes placed on the scalp and may detect abnormalities by comparing signals from the EEG logarithmic spectrum to reference data, through statistical parametric mapping, using covariates such as age.[11] The development of electrophysiological source imaging allows for a tomographic version of the qEEG with good tridimensional resolution. The Cuban Neuroscience Center (CNEURO) has developed hardware and software to advance qEEG use in a wide range of settings.[12] 


\section{COLLABORATION}

This paper describes a collaboration that began in 2016 to identify brain biomarkers of early childhood malnutrition and their association with impaired cognitive and behavioral outcomes. Scientific partners in this research effort are CNEURO, the Chester M. Pierce MD Division of Global Psychiatry at the Massachusetts General Hospital (MGH), the Center on the Developing Child at Harvard University, the Barbados Nutrition Study, and the Joint China-Cuba Lab of the University of Electronic Science and Technology of China.

Objectives The main purpose of the current study is to identify neural markers of early childhood malnutrition using qEEG and to apply a model of disease progression or accumulated risk of brain damage to test qEEG predictive capacity. Using archival BNS data, our model will include data on several childhood adversities that commonly co-occur-malnutrition, poverty, maternal depression and child maltreatment. We will also collect qEEG data in BNS study participants who are now aged 45-51 years and will compare these findings with qEEG data from 1977-78, when participants were aged 5-11 years. Cuban MEDICID neurometric equipment will be utilized in Barbados for this purpose.

Our research to date has identified two candidate biomarkers: increased delta and theta activity and decreased alphawave on EEG, an electrophysiological pattern we observed in children with histories of PEM but not in controls with healthy neurodevelopment. These EEG findings contribute to an analytical framework that includes measures of clinical, cognitive and behavioral outcomes assessed in childhood and subsequently over a span of four decades in the same cohort. In order to refine neural markers identified by qEEG and deepen our understanding of childhood malnutrition's long-term effects, we also plan to incorporate MRI to detect structural brain changes and near-infrared spectroscopy to gain additional information about brain function and dynamics.

Lastly, the project includes plans to use qEEG in other low resource settings where our research team has established collaborations.

\section{JUSTIFICATION}

This collaboration began in the early 1970's with BNS and members of the New York University Brain Lab, led by Professor E. Roy John. Lab members, including Drs Pedro Valdés Sosa, Leslie Prichep and others, published an article on computerassisted neurometrics in Science in 1977[13] and a subsequent Science report [14] using BNS control-group data from 1977-78. However, a comparison of these data in both PEM and control groups has not yet been published.

Janina R. Galler cofounded the BNS (with Sir Frank C. Ramsey) and has studied its participants (some of whom are now in their sixth decade) and their 2nd- and 3rd-generation offspring continuously since the early 1970's. Her link with Cuba dates to 1973 when her collaboration with Prof. John began. From 1976, Dr Galler served as a UNDP advisor to the Cuban Ministry of Public Health, and in 1985, she was a keynote speaker at the first Pan American Pediatric Congress in Havana. More recently, CNEURO and BNS have come together in a joint mission to enable improved multidisciplinary nutrition studies in the
Caribbean (centered in Barbados and Cuba) and pave the way for similar studies elsewhere in the Americas and in Africa, with potential benefits for population and health strategies. CNEURO will be setting up a qEEG laboratory in BNS over the next several months to further these efforts.

\section{PARTICIPANTS}

Participating institutions in the initiative are CNEURO, BNS, $\mathrm{MGH}$, Harvard University's Center on the Developing Child, and the Joint China-Cuba Lab for Frontiers Research in Translational Neurotechnology at the University of Electronic Science and Technology of China.

BNS This study was established to document the effects of early childhood malnutrition in Barbadian children born between 1967 and 1973, when severe malnutrition was a major public health problem on the island (no longer the case). In 1977, the BNS selected 129 children with clinically diagnosed moderate to severe marasmus (PEM marasmus group) who were aged 3 months to 1 year and met the following inclusion criteria: birth weight $>2500 \mathrm{~g}$, no pre- or postnatal complications, no brain injuries, and Apgar score >8. [3-5] The children were included in a national intervention program that followed all malnourished children in Barbados from birth to age 12 years and provided routine medical care, subsidized food, home visitation, nutrition education for their primary caretakers and twiceweekly preschool education.[15] None of the children in the PEM group experienced a further episode of malnutrition.

For each child in the PEM (marasmus) group, the study recruited a classmate of the same age, sex and handedness who met the same inclusion criteria but did not have a history of malnutrition (control group). In 1984, a third group of children with documented kwashiorkor during the first year of life was incorporated into the study (PEM kwashiorkor group).

Over the past 45 years, the BNS has collected medical, epigenetic, neuropsychological, behavioral, academic performance and social data.[3-9] Since 1973, systematic followup has been conducted on all study participants (generation 1), their parents (generation 0), and their immediate descendants (generation 2).[16] Household standard of living, maternal depression, child maltreatment and other adverse conditions were also documented.[17,18]

BNS has continued to actively study $56 \%$ of the original group of participants recruited in $1973-76$, and $75 \%$ of eligible participants who still reside in Barbados have been in seven waves of data collection over 45-51 years. Currently 206 immediate descendants of the original cohort (now aged 6-30 years) are being studied. This research has been supplemented with multidisciplinary studies in animal models of protein-energy malnutrition.[19] For these reasons, BNS is a unique longitudinal study of individuals with histories of early childhood malnutrition. For a detailed description of the several waves of data collection see Figure 1.

Between 1977 and 1978, EEGs were recorded in participants from control and PEM (marasmus) groups, but only results from the controls were published as part of a normative, cross-cultural study of childhood qEEG. The effects of early malnutrition on qEEG from this study have not yet been 
Figure 1: Barbados Nutrition Study data collection waves

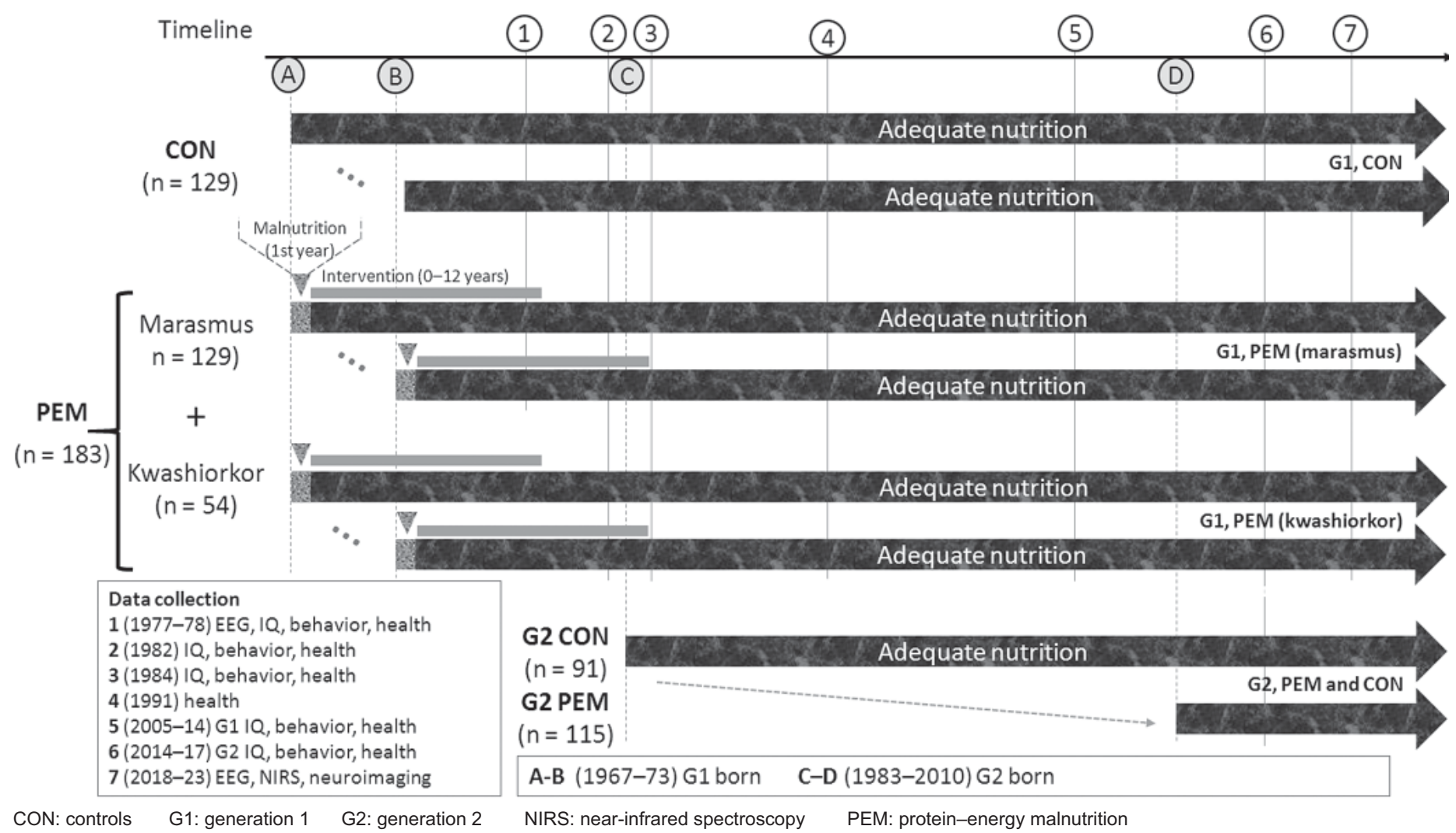

published, nor has the possibility of identifying biomarkers been fully explored.

MGH The original and largest teaching hospital of Harvard Medical School, MGH is considered one of the top five hospitals in the USA. The Chester M. Pierce MD Division of Global Psychiatry is one of the first US programs for global mental health and serves as a site for global mental health expertise and a source of collaboration in international efforts aimed at reducing the global burden of mental illness.

Center on the Developing Child at Harvard University The Center focuses on the development of children who have experienced adverse conditions early in life. Its areas of work are childhood nutrition, global health, early toxic stress, and brain development. The Center seeks transformational improvements in lifelong learning, behavior and both physical and mental health among children facing adversity.

CNEURO Valdés-Sosa and other founders of CNEURO were the first in Cuba to conduct computer-assisted assessment of brain disorders, using a computer donated by US scientists in 1969. By 1970, they developed the first Cuban computer for EEG analysis. In the early 1990s, Cuba was the first country to systematically introduce qEEG into its public health system. [20] Few research centers in the world have been as influential as CNEURO in quantitative analysis of electrical activity in the brain.[21,22]

In Cuba, CNEURO coordinates the neuroscience programs of the Ministry of Science, Technology and the Environment, which includes other research centers, universities (including the two with which the Cuban authors of this paper are associated), hospitals and health centers. This leadership extends beyond Cuba to other parts of the Caribbean, Latin America and Asia. [23] CNEURO has developed successful national programs for hierarchical screening in Cuba and Ecuador to identify and treat problems related to brain functioning.[10]

Joint China-Cuba Lab for Frontier Research in Translational Neurotechnology Currently PAVS directs the laboratory at the University of Electronic Science and Technology of China, which has developed program packets for preprocessing and analysis of EEG data obtained from BNS (both control and PEM groups) in 1977-78. The lab continues to develop qEEG tomographic tools for this purpose.

Financing The collaboration's initial activities were financed by participating institutions, as detailed in memoranda of understanding. Subsequently, the Nestlé Foundation for the Study of Problems of Nutrition in the World, headquartered in Lausanne, Switzerland, provided funding. NIH funding supports the ongoing BNS intergenerational study of childhood malnutrition, which includes collection of epigenetic, health, neuropsychological and behavioral data.

\section{ACTIVITIES}

The aims of this new collaborative study are to collect EEG data in adults aged 45-51 years who were tested 45 years earlier $(1977-1978)$ and to confirm the predictive value of the qEEG for malnutrition effects over the lifespan and across 
generations by identifying biomarkers, a unique opportunity provided by BNS.

Table 1 summarizes the initiative's main activities. Activities 1-4 are nearly complete. Activities 5-7 are ongoing and will be partially financed by a grant from the Nestlé Foundation.

Recognizing that childhood malnutrition occurs in the context of poverty and other adversities, we propose to employ a model of progressive brain damage that could reveal the independent and combined effects of accumulated risk from exposure to a variety of childhood adversities, including malnutrition, poverty, maternal depression and child maltreatment. Finally, comparisons of EEG data collected four decades ago in childhood with more recent adult data in the same cohort will facilitate identification of neural markers of early childhood malnutrition and its long-term and intergenerational effects on brain, cognition and behavior.

Estimates of power spectral density at frequencies between $0.78 \mathrm{~Hz}$ and $19.14 \mathrm{~Hz}$, with a $0.39 \mathrm{~Hz}$ frequency-step, as part of quantitative analysis were applied to the preprocessed information. Statistical analysis, was conducted, correcting for multiple comparisons using permutations. Significant differences were found between groups, using ANCOVA specific to the channel and frequency curve (19.48), according to regression by age. Differences were demonstrated between EEG data of PEM and control participants, which can predict functional differences between PEM and control participants. In this first analysis of qEEG, biomarkers are present as bands in the low frequencies (delta and theta) of the EEG and are specific to the group that experienced PEM in the first year of life.

The current study will recruit a subgroup of original research participants (50 PEM and 50 controls) to undergo repeat testing, including EEGs, at ages $45-51$ years. BNS has proven experience in recruiting and tracking participants, and in performing behavioral, cognitive and health assessments. CNEURO staff has vast experience in field work, EEG recordings, and analysis of electrophysiological data, which will facilitate our goal of identifying neural biomarkers of early malnutrition.
As part of this collaboration, 137 EEG records (54 PEM and 83 controls) were located out of a total of 258 (129 PEM and 129 controls) obtained in 1977-1978 in Barbados. Following review by two specialists (who recommended discarding records with evidence of sleep during testing), a total of 108 valid EEG records (46 PEM and 62 controls) remained, with 19 derivations from the 10-20 international system, sampled at $100 \mathrm{~Hz}$. EEG data were preprocessed to automatically reduce electromyographic and electrooculograpic artifacts, using independent component analysis.

Articles describing new findings and newly identified biomarkers will be published at all stages of this initiative to facilitate development of targeted interventions for children suffering from early childhood malnutrition. The first article is being prepared for submission in 2018.

Ethics Written informed consent was provided by all BNS participants under the oversight of the MGH IRB (IRB Protocol 2015P000329/MGH). All BNS research was approved by the Barbados Ministry of Health. MGH participants were compensated for travel and time taken off from work. Future data collection and research will follow similar ethical guidelines, as established by the Declaration of Helsinki and International Committee of Medical Journal Editors guidelines.[24,25]

\section{RESULTS AND BENEFITS}

A report on the results of analyses of childhood EEGs from 197778 is currently in preparation. Software packages have been used to prepare qEEG data for preprocessing and analysis. A model of disease progression or accumulated risk of brain damage is being developed to identify the mechanisms whereby PEM during the first year of life may affect neurodevelopment and impair cognition and behavior over the life span and across generations.

During the project, participating centers will benefit from training in electrophysiological methodologies, field methods, longitudinal data collection, and technology transfer and staff training. As translational research, it will ultimately benefit public health systems where the findings obtained here are applied.

Table 1: Barbados Nutrition Study collaborative activities, 2017 forward

\begin{tabular}{|c|c|c|c|}
\hline Activity & Year & Location & Products/Comments \\
\hline $\begin{array}{l}\text { 1. Locate and transfer } 1977-78 \text { childhood EEG } \\
\text { recordings }\end{array}$ & 2017 & USA & EEG database (raw) \\
\hline $\begin{array}{l}\text { 2. Recover EEG data: change format, preprocessing, } \\
\text { preliminary analyses }\end{array}$ & 2017 & Cuba, China & EEG (preprocessed) database, MATLAB programs \\
\hline $\begin{array}{l}\text { 3. Statistical analyses comparing PEM and CON using } \\
\text { qEEG, search for biomarkers }\end{array}$ & 2017 & Cuba, China & $\begin{array}{l}\text { Toolboxes in MATLAB to process EEG data } \\
\text { Article submitted to Frontiers in Neuroscience special issue, Energy } \\
\text { Efficient Neural Code in Individual Neurons and Brain Circuits }\end{array}$ \\
\hline 6. Record EEGs and NIRS in PEM and CON adults & 2018 & Barbados & Creation of new longitudinal and multimodal database \\
\hline $\begin{array}{l}\text { 7. Analysis of qEEG (comparing 1977-78 and } 2018 \\
\text { recordings) }\end{array}$ & 2018 & Cuba & Article published \\
\hline $\begin{array}{l}\text { 8. Recruit participants (PEM and CON) and conduct } \\
\text { MRI, cognitive and behavioral tests }\end{array}$ & - & - & Multimodal databases \\
\hline
\end{tabular}

BNS:Barbados Nutrition Study CON: control group G1: generation 1 NIRS: near-infrared spectroscopy PEM: protein-energy malnutrition group qEEG: qualitative electroencephalography 
As the project evolves, biomarkers will be refined with data from near-infrared spectroscopy and magnetic resonance imaging that will also be collected in selected study participants. Lastly, field testing can be extended to other low-resource settings, such as African countries with high malnutrition prevalence and with which scientific collaboration already exists.

This is the first time that qEEG has been used to evaluate the effects of early childhood malnutrition on the central nervous system and to identify biomarkers to objectively assess children at greatest risk for neurodevelopmental delays and disabilities in developing countries and to assist in the development of targeted interventions for high-risk children in these settings.

\section{ACKNOWLEDGMENTS}

This research was developed with the cooperation of the Ministry of Health of Barbados and financed by grant $\mathrm{NIH}$, and by $\mathrm{R} 01$ HD060986 (JRG) from the US NIH and the Nestle Foundation (PAVS). The authors thank the research participants, their families and the BNS team, as well as Sir Frank C. Ramsey and Prof. E. Roy John, both deceased, who pioneered this study. $-1 /$ -

\section{REFERENCES}

1. Gomez F, Galvan RR, Cravioto J, Frenk S. Malnutrition in infancy and childhood, with special reference to kwashiorkor. Adv Pediatr. 1955;7:131-69

2. Imagine a world free from hunger and malnutrition. Lancet [Internet]. 2017 Sep 30 [cited 2017 Oct 20];390(10102):1563. Available from: http://linkinghub.elsevier.com/retrieve/pii/ S0140673617325497

3. Galler JR, Bryce CP, Waber DP, Hock RS, Harrison $\mathrm{R}$, Eaglesfield $\mathrm{GD}$, et al. Infant malnutrition predicts conduct problems in adolescents. Nutr Neurosci [Internet]. 2012 Jul [cited 2017 Oct 20];15(4):186-92. Available from: https://www .ncbi.nlm.nih.gov/pmc/articles/pmid/22584048/

4. Galler JR, Bryce CP, Zichlin ML, Waber DP, Exner N, Fitzmaurice GM, et al. Malnutrition in the first year of life and personality at age 40 . J Child Psychol Psychiatry [Internet]. 2013 Aug [cited 2017 Oct 20];54(8):911-9. Available from: http://dx.doi.org/10.1111/jcpp.12066

5. Waber DP, Bryce CP, Girard JM, Zichlin M, Fitzmaurice GM, Galler JR. Impaired IQ and academic skills in adults who experienced moderate to severe infantile malnutrition: a 40-year study. Nutr Neurosci [Internet]. 2014 Feb [cited 2017 Oct 20];17(2):58-64. Available from: http:// www.tandfonline.com/doi/full/10.1179/14768305 13Y.0000000061

6. Galler J, Rabinowitz DG. The intergenerational effects of early adversity. Prog Mol Biol Transl Sci [Internet]. 2014 [cited 2017 Oct 20];128:177-98. Available from: https://linkinghub.elsevier.com/ retrieve/pii/B978-0-12-800977-2.00007-3

7. Waber DP, Bryce CP, Girard JM, Fischer LK, Fitzmaurice GM, Galler JR. Parental history of moderate to severe infantile malnutrition is associated with cognitive deficits in their adult offspring. Nutr Neurosci [Internet]. 2016 Nov 25 [cited 2017 Oct 20];25:1-7. Available from: http:// www.tandfonline.com/doi/full/10.1080/102841 5X.2016.1258379

8. Waber DP, Bryce CP, Fitzmaurice GM, Zichlin M, McGaughy J, Girard JM, et al. Neuropsychological Outcomes at Mid-Life Following Moderate to Severe Malnutrition in Infancy. Neuropsychology [Internet]. 2014 Jul [cited 2017 Oct 20];28(4): 530-40. Available from: http://content.apa.org/ journals/neu/28/4/530

9. Galler JR, Bryce C, Waber DP, Zichlin ML, Fitzmaurice GM, Eaglesfield D. Socioeconomic Outcomes in Adults Malnourished in the First Year of Life: A 40-Year Study. Pediatrics [Internet]. 2012 Jul [cited 2017 Oct 20];130(1): e1-e7. Available from: http://pediatrics.aap publications.org/cgi/pmidlookup?view=long\&pm id $=22732170$

10. Valdés-Sosa PA, Obrador-Fragoso A. Stratified active screening: where neurotechnology meets public health. MEDICC Rev [Internet]. 2009 Jan [cited 2017 Oct 20];11(1):7-10. Available from: http://www.medicc.org/mediccreview/index .php?get=2009/1/7

11. Bosch-Bayard J, Valdés-Sosa P, ViruesAlba T, Aubert-Vázquez E, John ER, Harmony $\mathrm{T}$, et al. 3D statistical parametric mapping of EEG source spectra by means of variable resolution electromagnetic tomography (VARETA). Clin Electroencephalogr [Internet]. 2001 Apr;32(2):47-61. Available from: http://journals.sagepub.com/ doi/abs/10.1177/155005940103200203

12. Szava S, Valdés P, Biscay R, Galan L, Bosch J, Clark I, et al. High resolution quantitative EEG analysis. Brain Topogr [Internet]. 1994 Spring [cited 2017 Oct 20];6(3):211-9. Available from: https://link.springer.com/article/10.1007/ BF01187711

13. John ER, Karmel BZ, Corning WC, Easton P, Brown D, Ahn $\mathrm{H}$, et al. Numerical taxonomy identifies different profiles of brain functions within groups of behaviorally similar people'. Science [Internet]. 1977 Jun 24 [cited 2017 Oct 20];196(4297):1393-409. Available from: http:// eslab.bu.edu/publications/articles/1977/john 1977neurometrics.pdf

14. Ahn H, Prichep L, John ER, Baird H, Trepetin M, Kaye $\mathrm{H}$. Developmental equations reflect brain dysfunctions. Science [Internet]. 1980 De 12 [cited 2017 Oct 20];210(4475):1259-62. http:// science.sciencemag.org/content/210/4475/1259

15. Ramsey FC. Protein-Energy Malnutrition in Barbados: The Role of Continuity of Care in Management. New York: Josiah Macy, Jr Foundation; 1979. $173 \mathrm{p}$.

16. Peter CJ, Fischer LK, Kundakovic M, Garg P, Jakovcevski M, Dincer A, et al. DNA Methylation Signatures of Early Childhood Malnutrition Associated With Impairments in Attention and Cognition. Biol Psychiatry. 2016 Nov 15 [cited: 2017 Oct 20];80(10):765-74. Available from: https://linkinghub.elsevier.com/retrieve/pii/S0006 $-3223(16) 32233-8$

17. Hock RS, Bryce CP, Waber DP, McCuskee S, Fitzmaurice GM, Henderson DC, et al. Relationship between infant malnutrition and childhood maltreatment in a Barbados lifespan cohort. Vulnerable Children Youth Studies. 2017 Sep 6;12(4):304-16.

18. Salt P, Galler JR, Ramsey F. The influence of early malnutrition on subsequent behavioral development. VII: The effects of maternal depressive symptoms. J Dev Behav Pediatr [Internet]. 1988 Feb [cited 2017 Oct 20];9(1):1-5. Available from: http://psycnet.apa.org/record/1988-20685-001

19. Fischer LK, McGaughy JA, Bradshaw SE, Weissner WJ, Amaral AC, Rosene DL, et al. Prenatal protein level impacts homing behavior in LongEvans rat pups. Nutr Neurosci [Internet]. 2016 Jun [cited 2017 Oct 20];19(5):187-95. Available from: http://www.tandfonline.com/doi/full/10.1179 /1476830515Y.0000000001
20. Valdés P, Valdés M, Carballo JA, Álvarez A, Díaz GF, Biscay R, et al. QEEG in a public health system. Brain Topogr. 1992 Jun [cited 2017 Oct 20];4(4):259-66. Available from: https://link .springer.com/article/10.1007\%2FBF01135563? LI=true

21. Cohen MS, Hillyard SA, Galler JR, Neville HJ, Rasenick MM, Reeves AJ, et al. Opinion: Advancing neuroscience interactions with Cuba. Proc Natl Acad Sci U S A [Internet]. 2015 May 12 [cited 2017 Oct 20];112(19):5859-61. Available from: http://www.pnas.org/cgi/pmidlookup?view= long\&pmid=25883271

22. Hernández-González G, Bringas-Vega ML, Galan-García L, Bosch-Bayard J, LorenzoCeballos Y, Melie-García L, et al. Multimodal quantitative neuroimaging databases and methods: the Cuban Human Brain Mapping Project. Clin EEG Neurosci [Internet]. 2011 Jul [cited 2017 Oct 20];42(3):149-59. Available from: http://journals.sagepub.com/doi/abs /10.1177/155005941104200303

23. Uludağ K, Evans AC, Della-Maggiore V, Kochen $S$, Amaro E, Sierra O, et al. Latin American Brain Mapping Network (LABMAN). Neuroimage [Internet]. 2009 Aug 1 [cited 2017 Oct 20];47(1):312-3. http://www.sciencedirect.com/science/article/pii/ S1053811909002869

24. World Medical Association. Declaration of Helsinki: ethical principles for medical research involving human subjects. JAMA [Internet]. $2013 \mathrm{Nov}$ 27 [cited 2017 Oct 20];310(20):2191-4. Available from: https://jamanetwork.com/journals/jama/fullarticle/10.1001/jama.2013.281053

25. International Committee of Medical Journal Editors. Recommendations for the Conduct, Reporting, Editing, and Publication of Scholarly Work in Medical Journals. Philadelphia: ICMJE; [updated 2017 Dec]; [cited 2017 Oct 20]. 19 p. Available from: http://icmje.org/icmje-recommendations.pdf

\section{THE AUTHORS}

Pedro A. Valdés-Sosa (Corresponding author: pedro.valdes@neuroinformatics-collaboratory. org; peter@cneuro.edu.cu.), physician with higher degrees in biological sciences and mathematics, Clinical Hospital of Chengdu Brain Science Institute, MOE Key Lab for Neuroinformation, University of Electronic Science and Technology of China, Chengdu, China; and Cuban Neuroscience Center (CNEURO), Havana, Cuba.

Janina R. Galler, psychiatrist. Professor of Psychiatry, Harvard Medical School; psychiatrist, Chester M. Pierce MD Division of Global Psychiatry, Massachusetts General Hospital (MGH), Boston, USA; faculty member, Center 
on the Developing Child, Harvard University, Cambridge (MA), USA.

Cyralene P. Bryce, psychiatrist. Senior Consultant, Field Director, Barbados Nutrition Study, and senior consultant, Queen Elizabeth Hospital, St. Michael, Barbados.

Arielle G. Rabinowitz, postgraduate research coordinator, Chester M. Pierce MD Division of Global Psychiatry, MGH, Boston, Massachusetts, USA.
María L. Bringas-Vega, psychologist, Clinical Hospital of Chengdu Brain Science Institute, MOE Key Lab for Neuroinformation, University of Electronic Science and Technology of China (UESTC), Chengdu, China; and CNEURO, Havana, Cuba.

Nibaldo Hernández-Mesa, neuroscientist. Professor emeritus, Medical University of Havana, Cuba.

Alberto Taboada-Crispi, electrical engineer, Clinical Hospital of Chengdu Brain Science
Institute, MOE Key Lab for Neuroinformation, UESTC, Chengdu, China; and Center for Computing Research, Central University of Las Villas, Santa Clara, Cuba.

Submitted: October 27, 2017

Approved for publication: March 24, 2018

Disclosures: None

\section{PsicoHabana 2018}

\section{7th International Conference on Psychiatry and Clinical Psychology}

\section{Havana's International Conference Center}

\section{September 19-21, 2018}

\section{Topics}

- Community psychology

- Client-centered psychiatry

- Ethics, human rights and psychiatry

- Sexuality, violence, gender and mental health

- Mental health rehabilitation

- Comprehensive mental health care for older adults

- Forensic psychiatry and psychology

- Addictions prevention and management

- Approaches to dual pathologies

- Neurosciences, genetics and epigenetics and mental illness

- Mental health nursing

- Psychoballet, hypnosis and other psychotherapeutic modalities

- Mental health services management, human resources

- Natural \& traditional medicine and mental health

Information: vdp.hph@infomed.sld.cu promociondeeventos.sld.cu/psicohabana2018 Host: Eduardo B. Ordaz Psychiatric Hospital 